\title{
The Human Fish Challenges with the Management of a Massive Air Leak after Pleurectomy
}

\section{Martinez-Ruiz R ${ }^{1}$, Matadial CM${ }^{1}$, Benitez-Lopez $\mathrm{J}^{1}$ and Villamizar-} Ortiz $\mathrm{N}^{2}$

${ }^{1}$ Department of Anesthesiology, Perioperative Medicine and Pain Management, University of Miami Miller School of Medicine, USA

${ }^{2}$ Department of Surgery, University of Miami Miller School of Medicine, USA

\section{Case Report}

Volume 1 Issue 1

Received Date: December 28, 2016

Published Date: February 07, 2017

*Corresponding author: Ricardo Martinez Ruiz, Department of Critical Care Medicine-Anesthesiology, University of Miami, USA, E-mail: Martinez_ruiz@yahoo.com

\section{Introduction}

The human respiratory system is usually our"gold standard" when we compare other species' respiratory systems; however, human lungs happen to be very inefficient compared to the gills in fish or the avian respiratory system. Try transferring oxygen $\left(\mathrm{O}_{2}\right)$ from low $\mathrm{O}_{2}$ water content or flying above Everest without supplemental $\mathrm{O}_{2}$ ! One of the reasons for the apparent inefficiency stems from the fact that the human respiratory system (like any mammal) has dead space: a common airway for the entry and exhaust of gases. This dilutes the inspired $\mathrm{O}_{2}$ as it gets to the alveoli. Respiratory systems that can minimize dead space have the ability to increase the $\mathrm{O}_{2}$ concentration reaching the gas exchange area. We describe here the management of a massive air leak after right pleurectomy. The magnitude of theair leak that ensued made the patient's respiratory system behave more like fish gills, enhancing carbon dioxide $\left(\mathrm{CO}_{2}\right)$ elimination in a highly "non-mammalian" manner.

This case is that of a 71 year old male $(70 \mathrm{Kg}$ ) who presented with mesothelioma treated with chemotherapy over the preceding 6 years. At this point a multidisciplinary tumor board deemed that he would benefit from a pleurectomy+/- extra pleural pneumonectomy. His pulmonary function tests were marginal and he had a calculated/predicted high risk of morbidity/mortality for pneumonectomy. At the time of surgery, which took approximately eight hours, the parietal and visceral pleura were removed with significant blood loss of over $2500 \mathrm{~mL}$. A low vascular tone state developed requiring initiation of vasopressor therapy. At the time ofright lung re-expansion, a massive air leak was noted. We were unable to adequately ventilate with our anesthesia machine (Datex-Ohmeda Avance-S5) despite maximal flows $(>15 \mathrm{~L} / \mathrm{min})$, as the bellows woulddeflate within 1-2 delivered tidal volumes. The ventilator mode was switched to manual, and the adjustable pressure-limiting ("flush") valve was used to fill the reservoirbag and provide a nominaltidal volume (Vt). Air was seen escaping (fluttering) past the incision as the surgeons were approximating the incisional edges during closure. In an effort to attempt to provide more efficient ventilation, an ICU ventilator was brought to the $\mathrm{OR}$ and thissuccessfully provided enough flow to compensate for the air leak. In addition to chest wall approximation, 4 thoracostomy tubes were placed in the pleural space. Intraoperatively, initially the Vt from the ICU ventilator was set to $400 \mathrm{ml}$ (for lung protection) and the expired Vt was $100 \mathrm{ml}$. Total (inspired) minute ventilation (MV) was $6 \mathrm{~L} / \mathrm{min}$. The first blood gas revealed a severe respiratory alkalosis $(\mathrm{pH}=7.62)$ with $\mathrm{PaCO}_{2}$ in the high teens. MV was reduced to $2 \mathrm{~L} / \mathrm{m}$ and the new PaCO2was in the mid 20's.

The patient was transferred to the ICU and the 4 chest tubes were connected to suction $(-20 \mathrm{cmH} 20)$. The ensuing air leak was significant and chest tube suction was lowered to $-10 \mathrm{cmH} 20$. Minute Ventilation was kept very low as the patient remained with significant respiratory alkalosis. We sampled the chest tube output from each of the 4 chest tubes with a capnograph and the exhaust had an average of 0.7-0.9 \% $\mathrm{FeCO}_{2}$ (normal 


\section{Open Access Journal of Pulmonary \& Respiratory Sciences}

exhaled $\mathrm{FeCO}_{2} \sim 5 \%$ ). It was apparent then, that the air leak gas had participated in gas exchange and was being eliminated via the chest tubes. We were unable to quantify the total leak as the Wright respirometer's turbine would not sense or be moved with the constant low flows of the leak in each individual chest tube. The flow and volume traces in the ventilator were noteworthy (Figure 1). The ventilator integrates the flow trace to give volume. The Vt delivered was $\sim 225 \mathrm{ml}$ (red arrow) (despite setting the Ventilator to $430 \mathrm{ml}$ in the pressure control/volume guaranteed mode) $\mathrm{x} 7=1575 \mathrm{ml}$ of MV. The machine was measuring a total MV of $3.42 \mathrm{l} / \mathrm{m}$. The difference of almost $2 \mathrm{~L} / \mathrm{min}$ thereforerepresents the air leak flushing the $\mathrm{CO}_{2}$ into the chest tube. The leak can be seen in the volume trace (blue arrow). As the ventilator kept giving flow (to maintain airway pressure at the Peep level), the flow is integrated over time and gives a volume of around $300 \mathrm{ml}$ (blue arrow) per breath. The flow through the leak thus seemed to be a very efficient way of eliminating $\mathrm{CO}_{2}$ as the gas went in one direction, cutting down significantly on dead space. This gas exchange resembled the gas exchange that occurs at the gills in fish, where the water enters the mouth of the fish and exits through the gills, eliminating dead space (no common path between inhaled and exhaled water or air in the case of humans). As the air leak improved over the subsequent days, the minute ventilation on our ventilator was increased accordingly to compensate for the decreased $\mathrm{CO}_{2}$ elimination from the decreasing air leak. The patient was eventually weaned off ventilator support and was discharged to a long term facility 1 month after his initial surgery.

\section{Discussion}

It is important to realize that significant air leaks can create major issues, especially with an OR ventilatorwhich cannot adequately compensatefor the massive volume loss despite maximal flows. Utilizing an ICU ventilator in the OR, with its higher flow capacity, seemed to solve this problem. Also, the understanding that the air leaks being produced from the visceral pleural dissection will generate an air leak containing significant $\mathrm{CO}_{2}$ (distinct from that of the air leak produced from a bronchopleural fistula, where the gas exiting the fistula has not participated in gas exchange in a significant fashion), will require the adjustment of the MV to avoid severe respiratory alkalosis. We had to reduce the minute ventilation to avoid severe respiratory alkalosis as we were eliminating significant amounts of $\mathrm{CO}_{2}$ via the air leaks. Bishop, et al. [1] had reported $\mathrm{CO}_{2}$ elimination in airleaks in ARDS patients. Some of his patients had end tidal $\mathrm{CO}_{2}$ that were lower than the expired $\mathrm{CO}_{2}$ concentration in the chest tubes! The presence of dead space in our mammalian respiratory system is necessary as air needs to be "conditioned" before it gets to the alveoli. This introduces some level of inefficiency as the alveolar oxygen is diluted by the expired $\mathrm{CO}_{2}$ reducing the alveolar partial pressure of $\mathrm{O}_{2}$. Animals that have developed respiratory systems that reduce (birds) or almost eliminate (fish) dead space can survive in conditions where mammalian lungs will not be able to provide for adequate oxygenation. Gills are designed to have water entering the fish's mouth and exiting through the gills as oxygen is exchanged with blood in a countercurrent gas exchange mechanism [2]. This allows for a very efficient system were the blood exiting the gills will have the same partial pressure of $\mathrm{O}_{2}$ than the water entering the gills. In our lungs, there is a $60 \mathrm{mmHg}$ partial pressure drop of $\mathrm{O}_{2}$ between the inspired partial pressure of $\mathrm{O}_{2}\left(\mathrm{PiO}_{2}\right)$ and the $\mathrm{PaO}_{2}$ in arterial blood.

Our patient had severe air leaks that contained $\mathrm{CO}_{2}$. The gas from these leaks was not returning to the exhaled air but escaping the respiratory system creating a oneway path for air (similar to the path of water in the gills). In practical terms, dead space had been eliminated. This increased efficiency in $\mathrm{CO}_{2}$ eliminationexplains how, despite a low minute ventilation, our patient was severely hypocapnic.

Of interest, a number of fish have evolved so-called accessory breathing organs that extract oxygen from the air in similar fashion to mammalian lungs [3]. Breathing air is primarily of use to fish that inhabit shallow, seasonally variable waters where the water's oxygen concentration may seasonally decline. At the most extreme, some air-breathing fish are able to survive in damp burrows for weeks without water, entering a state of aestivation (summertime hibernation) until water returns. Facultative air breathers, such as the catfish, only breathe air if they need to and can otherwise rely on their gills for oxygen. Our patient basically behaved like a facultative air breather, relying on the elimination of $\mathrm{CO}_{2}$ via his air leak and slowly transitioning to regular inefficient mammalian lung $\mathrm{CO}_{2}$ elimination as the air leaks healed. One alternative to consider in the treatment of this patient was to use differential lung ventilation, where we could have put the lung with the leak on CPAP and ventilated the normal lung with appropriate volumes. This would have required keeping the double lumen tube in situ for a prolonged period of time and probably the air leak with the CPAP would have also cleared the $\mathrm{CO}_{2}$ as efficiently. As the air leaks improved over time, hence reducing the $\mathrm{CO}_{2}$ elimination, we had to increase the minute ventilation to maintain normocapnia. The patient 


\section{Open Access Journal of Pulmonary \& Respiratory Sciences}

was subsequently weaned and discharged to an extended

care facility one month after his original surgery.

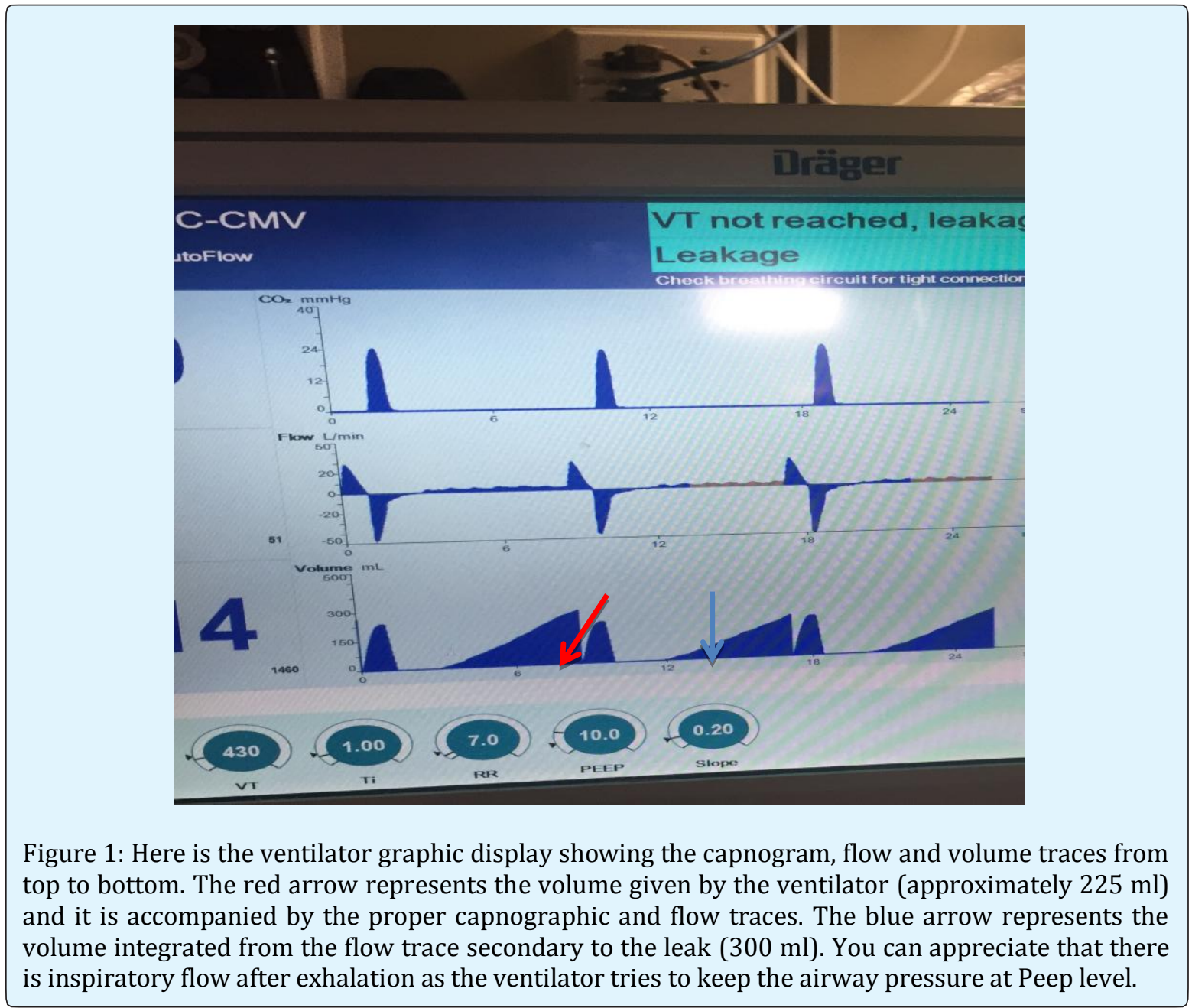

\section{References}

1. Bishop MJ, Benson MS, Pierson DJ (1987) Carbon Dioxide Excretion via Bronchopleural Fistulas in Adult Respiratory Distress Syndrome. Chest 91(3): 400-402.

2. Prosser CL (1991) Comparative Animal Physiology, Environmental and Metabolic Animal Physiology (4th edn), Hoboken, NJ: Wiley-Liss, pp. 1-12.
3. Hoar WS and Randall DJ (1984) Fish Physiology: Gills: Part A - Anatomy, gas transfer and acid-base regulation Academic Press. 